\title{
Relationship between attitudes to health, body weight and physical activity and level of physical activity in a nationally representative sample in the European Union
}

\author{
BM Margetts ${ }^{1}$, E Rogers ${ }^{1}, \mathrm{~K}$ Widhal ${ }^{2}, \mathrm{~A}-\mathrm{M}$ Remaut de Winter $^{3}$ and H-JF Zunft ${ }^{4}$ \\ ${ }^{1}$ Institute of Human Nutrition and Wessex Institute for Health Research and Development, \\ University of Southampton, Southampton, UK: ${ }^{2}$ University of Kinderlinik, Wien, Austria: \\ ${ }^{3}$ Faculty of Agriculture and Applied Biological Science, University of Gent, Gent, Belgium: \\ ${ }^{4}$ German Institute of Human Nutrition, Bergholz-Rehbruecke, Germany
}

\begin{abstract}
Objective: To explore the factors that influence attitudes and beliefs about the effects of body weight and physical activity on health.

Design: Cross-sectional survey using a face-to-face interview-assisted questionnaire. Setting: The survey was conducted between March and April 1997 in the 15 member states of the EU.

Subjects: Approximately 1000 adults aged 15 years plus from each country were selected by quota-controlled sampling; the total sample was of 15239 persons ( 7162 males and 8077 females). Data were weighted by population size for each country and by age, gender and regional distribution within countries.

Results: Overall 27\% of men and $35 \%$ of women reported not engaging in any form of recreational activity; rates were highest in those with a primary-level education $(37 \%$ men, 43\% women) compared with tertiary-level education ( $20 \%$ men, 25\% women). Recreational activity levels declined with age and tended to be lowest in those who were more physically active at work. Eighteen per cent of respondents believed that physical activity was one of the two greatest influences on health; 13\% mentioned body weight, 38\% mentioned food, 41\% mentioned smoking and 33\% mentioned stress. Logistic regression was used to assess for the effects of gender, age, educational level, body mass index (BMI), smoking status, activity level and country on beliefs that body weight and physical activity influenced health. Primary-educated, overweight, ex- and non-smoking women were most likely to mention body weight as an influence; young tertiary-educated, thinner, non-smoking and active males were most likely to mention physical activity. There was wide variation across Europe in reported behaviour and beliefs, which persisted after taking account of all of the other factors in the regression model.

Conclusions: Relatively few people in some countries believed body weight and physical activity were important influences on health. Many people mentioned stress and it might be possible to use this interest to motivate changes in physical activity to relieve stress. It may be important to take a more integrated approach to activity patterns that consider the role of work and recreation. Although social and demographic factors were important, after adjusting for these factors there was still wide between-country variation in reported attitudes, beliefs and behaviour. This will need to be taken into account in any activity promotion campaigns.
\end{abstract}

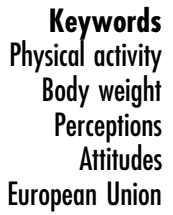

There is now substantial evidence that obesity is a major public health problem ${ }^{1}$. Evidence from cohort studies show that the risk of mortality rises almost linearly with increasing body weight ${ }^{2}$, and that most major chronic diseases are increased in the overweight ${ }^{1}$. The prevalence of obesity is rising in all countries where data exist. Physical inactivity is linked to obesity ${ }^{3,4}$. In the UK, national energy intakes have fallen over the last 10 years, while at the same time the prevalence of obesity has risen ${ }^{1}$. The most logical explanation for this is a change in patterns of work and leisure activity reducing energy expenditure ${ }^{5}$. Recent reviews of trials have shown that body weight can be reduced in primary-care-based activity promotion programmes, but that the evidence is inconsistent and affected by poor study design ${ }^{6,7}$. Further research is required.

Physical activity may affect risk of chronic diseases 
either through effects on energy balance or through a range of other physiological processes that are altered in those who engage in increased levels of activity $^{8}$. The health benefits of increased activity include changes in lipids and blood pressure, as well as in reduced levels of stress and improved general well-being.

The determinants of maintaining, or taking up, recreational physical activities are complex but are influenced by knowledge and attitudes, environmental and social influences and barriers and self-efficacy? Those who engage in recreational activities are more likely than those who do not to believe that these activities are beneficial to their health. Large-scale community intervention programmes have not been as successful as hoped, partly because they did not adopt a broad-based, community-wide approach ${ }^{10}$.

Across Europe there is little data on the factors influencing patterns of physical activity. The present study explores the factors that influence beliefs about the effects of body weight and physical activity on health.

\section{Methods}

The methods have been described in detail elsewhere $^{11}$. In brief, approximately 1000 adults aged 15 years or older were selected from each of the 15 member countries of the EU, except in Luxembourg where 500 adults were selected and in Germany where 1159 were selected (873 from former West Germany and 286 from former East Germany). The UK data also included Northern Ireland ( 250 subjects; 1250 in total). The total sample included in the present analysis was 15239 persons (7162 males and 8077 females). The sample in each country was quota-controlled to make the sample nationally representative. It was not possible to derive an estimate of the response rate as no data were available on the number of people contacted in each centre in order to achieve the quota sample.

A steering group, using as far as possible questions that had been used in previous studies, designed a questionnaire to be used for face-to-face interviews. Where possible closed questions were asked. Apart from questions related to the respondents' attitudes about influences on health and body weight, subjects were asked to provide information on: gender, age, income or occupation of the head of the household (the exact approach differed in each country), highest educational level, marital status, size of household, number of children, employment status and smoking status; they were also asked to estimate their own weight and height. It was felt that 'social class' (as defined in the UK by occupation of the head of the household) was likely to be a key factor within each country in determining attitudes about healthy eating. The UK approach to 'social class' was not considered appropriate for use across Europe; it was felt that of the three measures - income, occupation/ employment status and highest educational level only highest educational level could be interpreted in a consistent way for each country. We have therefore used highest educational level (referred to hereafter as educational level) as the key variable for defining 'social class'. Because 'social class' is a term not used widely outside the UK, it will not be used in this paper.

Subjects were selected and interviewed by a market research organization from each country. An omnibus approach was used; subjects answered questions on different topics from various clients in a single interview. Questionnaires were translated into the language used in each country, and were administered between March and April 1997. Only one person per household was interviewed. Where there was more than one eligible person resident in a household different approaches were used. In Austria the Kish grid $^{12}$ was used; in Denmark, Finland, Greece, Ireland, the Netherlands and Sweden the interviewer selected the individual whose next birthday was closest to the interview date; in the remaining countries the first eligible person to answer the door was interviewed.

Respondents were shown a list of nine factors (food, body weight, smoking, the environment, physical activity/exercise, alcohol intake, stress, genetics/ family predisposition, support from family and friends) and asked to select the two that they believe have the greatest influence on overall health. Respondents could also answer 'none of these' or 'don't know'.

Respondents were also asked, in an average week, which if any of a list of activities they participated in, and for how many hours. Respondents were also asked to describe their typical day's activity in terms of the numbers of hours spent sitting down, standing or in more physical work than either sitting or standing. These responses were subsequently grouped into three levels; less than 2 hours a day, 2-5 hours a day and 6 hours or more a day.

Because of the large sample size, small differences (of the order of $2-3 \%$ for whole-country estimates) between groups within the study were highly statistically significant $(P<0.0001)$. We were more concerned with important differences, and wanted to highlight areas of greatest contrast; for this reason we have not used statistical significance as a measure of the importance of differences between groups.

All results have been weighted for within- and between-country sampling variations, so that either total sample (weighted by population size in each country) or country-specific percentages (weighted by 
Table 1a Percentage of respondents in each member state who do not participate in any recreational activity, believe that activity has an important influence on health and average BMI classified by gender

\begin{tabular}{|c|c|c|c|c|c|c|c|}
\hline \multirow[b]{2}{*}{ Country } & \multirow[b]{2}{*}{ No. } & \multicolumn{2}{|c|}{$\begin{array}{l}\text { Do not participate } \\
\text { in any recreational } \\
\text { activities }\end{array}$} & \multicolumn{2}{|c|}{$\begin{array}{l}\text { Activity as important } \\
\text { influence on } \\
\text { health }\end{array}$} & \multicolumn{2}{|c|}{$\begin{array}{l}\text { Mean BMI } \\
\text { (SD) }\end{array}$} \\
\hline & & Male & Female & Male & Female & Male & Female \\
\hline Austria & 931 & 11.8 & 14.3 & 26.3 & 19.3 & $25.7(9.6)$ & $24.8(8.2)$ \\
\hline Belgium & 982 & 33.7 & 43.1 & 16.1 & 13.9 & $25.0(3.9)$ & $23.8(4.2)$ \\
\hline Denmark & 1147 & 21.3 & 23.8 & 42.6 & 30.4 & $25.1(4.2)$ & $23.7(5.2)$ \\
\hline Finland & 979 & 8.8 & 7.3 & 44.9 & 44.0 & $25.2(3.7)$ & $24.7(4.6)$ \\
\hline France & 1003 & 28.9 & 41.5 & 15.9 & 10.4 & $24.2(3.6)$ & $23.0(4.3)$ \\
\hline Germany & 1159 & 26.8 & 32.4 & 20.5 & 18.8 & $25.4(3.2)$ & $24.6(4.6)$ \\
\hline Greece & 1011 & 32.9 & 45.7 & 11.5 & 6.5 & $25.2(3.5)$ & $24.6(4.4)$ \\
\hline Ireland & 1001 & 12.9 & 13.9 & 35.1 & 27.2 & $25.0(3.8)$ & $24.0(4.1)$ \\
\hline Italy & 1000 & 34.0 & 40.9 & 11.8 & 6.6 & $24.9(3.5)$ & $23.5(4.0)$ \\
\hline Luxembourg & 518 & 17.8 & 17.9 & 12.5 & 8.4 & $25.0(4.6)$ & 24.0 (4.5) \\
\hline Netherlands & 1010 & 16.9 & 16.0 & 17.3 & 14.4 & $24.8(3.8)$ & $24.4(4.6)$ \\
\hline Portugal & 1007 & 49.5 & 70.0 & 13.7 & 8.6 & $25.1(3.6)$ & $24.7(4.2)$ \\
\hline Spain & 1000 & 32.8 & 40.0 & 17.6 & 13.3 & $25.3(5.4)$ & $24.6(4.4)$ \\
\hline Sweden & 1001 & 12.4 & 7.4 & 32.5 & 29.3 & $24.8(3.6)$ & $24.0(4.6)$ \\
\hline UK & 1490 & 19.4 & 26.8 & 29.6 & 25.0 & $25.0(4.1)$ & $24.5(4.8)$ \\
\hline Total & $15239^{*}$ & 27.2 & 34.6 & 19.7 & 15.6 & $25.0(3.8)$ & $24.2(4.6)$ \\
\hline
\end{tabular}

*Weighted according to population size.

Table 1b Percentage of respondents in each member state who currently smoke, are obese $(\mathrm{BMI} \geqslant 30)$ and believe that body weight is an important influence on health classified by gender

\begin{tabular}{|c|c|c|c|c|c|c|}
\hline \multirow[b]{2}{*}{ Country } & \multicolumn{2}{|c|}{$\begin{array}{l}\text { Current } \\
\text { smokers }\end{array}$} & \multicolumn{2}{|c|}{$\begin{array}{l}\text { Body weight as } \\
\text { important influence } \\
\text { on health }\end{array}$} & \multicolumn{2}{|c|}{ Obese } \\
\hline & Male & Female & Male & Female & Male & Female \\
\hline Austria & 32.0 & 22.0 & 7.6 & 9.3 & 11.3 & 10.0 \\
\hline Belgium & 34.3 & 28.4 & 18.1 & 23.7 & 10.2 & 8.6 \\
\hline Denmark & 41.2 & 33.2 & 11.9 & 10.8 & 8.9 & 7.4 \\
\hline Finland & 34.7 & 22.6 & 8.0 & 5.5 & 8.8 & 12.0 \\
\hline France & 54.7 & 37.6 & 10.4 & 17.6 & 7.3 & 7.1 \\
\hline Germany & 44.7 & 33.4 & 11.8 & 14.2 & 9.4 & 11.9 \\
\hline Greece & 50.4 & 33.2 & 15.4 & 15.9 & 8.7 & 12.3 \\
\hline Ireland & 33.8 & 30.2 & 17.3 & 20.2 & 9.4 & 7.3 \\
\hline Italy & 33.2 & 26.0 & 10.0 & 8.1 & 7.1 & 7.8 \\
\hline Luxembourg & 35.7 & 22.2 & 9.7 & 8.4 & 7.7 & 11.1 \\
\hline Netherlands & 47.0 & 38.2 & 14.3 & 11.4 & 7.8 & 11.5 \\
\hline Portugal & 38.5 & 10.5 & 10.6 & 21.4 & 7.3 & 10.8 \\
\hline Spain & 43.2 & 25.7 & 7.9 & 8.5 & 10.4 & 11.6 \\
\hline Sweden & 23.1 & 24.3 & 15.7 & 11.0 & 8.0 & 6.6 \\
\hline UK & 36.9 & 32.1 & 14.7 & 17.5 & 10.2 & 12.1 \\
\hline EU average* & 41.8 & 30.7 & 11.5 & 13.5 & 9.0 & 10.2 \\
\hline
\end{tabular}

*Weighted according to population size.

age, gender and region) should reflect the underlying prevalence in the population being sampled.

\section{Results}

Table 1 presents the number of respondents in each country and the percentage of respondents who do not engage in any form of recreational activity. Overall more women than men do not engage in any form of recreational physical activity $(34.6 \%$ for women compared with $27.2 \%$ for men). There was wide variation between countries in the percentages of men and women who do not participate in any recreational activities; rates were lowest in Finland (men 8.8\%; women 7.3\%) and highest in Portugal (men 49.5\%; women 70.0\%). Portugal, Spain, Italy, Greece and Belgium tended to have the highest rates of nonparticipation in recreational activities compared with Austria, Finland, Sweden and Ireland.

Respondents were asked to describe a typical day's activities grouped into hours spent sitting, standing and engaged in more physical work than either sitting or standing. The proportion spending more than 6 hours a day in more physical activities (overall 49.2\%) varied from around 60\% in France, Greece, Luxembourg, Portugal and Spain to around $40 \%$ in the UK, Ireland, Italy and the Netherlands. There was also some variation across Europe in the proportion of people 
spending more than 6 hours a day sitting down at home or work each day (range $43 \%$ in Greece to $29 \%$ in Ireland). There was some consistency across countries, although not absolutely, between the lower rates of participation in recreational activities and the higher rates of participation in more physical work. Nearly twice as many respondents who report spending more than 6 hours a day in more physical work are likely to mention no recreational activities as those who spend less than 2 hours a day in more physical work (men 25\% compared with $44 \%$; women $18 \%$ compared with $35 \%$ ).

Respondents were asked to select two factors (from a list of nine, with the possibility of answering 'don't know' and 'none of these' as well) that they believed had the greatest influence on overall health. Overall, $41 \%$ mentioned smoking, 38\% mentioned food, 33\% mentioned stress, $20 \%$ mentioned alcohol, 18\% mentioned physical activity, $16 \%$ mentioned environment, $13 \%$ mentioned body weight and 9\% mentioned genetics/metabolism. Less than $1 \%$ of respondents said they did not know, and about 1\% said none of the choices influenced health. Table 1 summarizes the country-specific percentages for those mentioning physical activity and body weight broken down by gender. Overall, men were more likely than women to mention physical activity, whereas the opposite was the case for body weight. There was wide variation, and a contrast in emphasis (but consistency between sexes within a country), between countries in the proportion of respondents mentioning physical activity (Greece $11.5 \%$ for men and 6.5\% for women compared with Finland $44.9 \%$ for men and $44.0 \%$ for women) and body weight (Finland $8.0 \%$ for men and $5.5 \%$ for women compared with Greece $15.4 \%$ for men and $15.9 \%$ for women).

Average self-reported BMI, percentage obese (BMI > 30) and percentage current smokers are also summarized in Table 1 for each country. The average BMI did not vary greatly across Europe, although men had a higher BMI than women. The prevalence of obesity was lowest in Swedish women (6.6\%) and highest in Greek women (12.3\%). Overall $41.8 \%$ of men and $30.7 \%$ of women smoked; Portuguese women the least (10.5\%) and French men the most (54.7\%). The prevalence of smoking was higher in Swedish women than men (24.3\% compared with $23.1 \%)$ in contrast to all other countries where the prevalence for men was higher, considerably so in Portugal (men 38.5\%, women $10.5 \%$ ).

Although there was considerable variation between countries, Table 2 summarizes the relationship between educational level, age and tendency not to engage in recreational activity and the likelihood of mentioning body weight or physical activity as an influence on health. Among men with a tertiary education, those under the age of 44 years were the most likely to engage in recreational activities. For men with primary-level education, there was a trend with age, but overall levels of recreational activity were lower and declined more steeply with age. Nearly twice as many women (43.3\%) with only a primary-level education compared with a tertiary education (24.9\%) did not engage in any recreational activities. Among those respondents under 65 years of age, there was a strong trend for tertiary-educated people to spend more than 6 hours a day at work or home sitting, whereas there was little difference in the proportion engaged in more physical activities over the day (for example, in the youngest age group those spending more than 6 hours a day in more physical activities were $41 \%, 43 \%$ and $45 \%$ for primary, secondary and tertiary-educated groups, respectively).

For respondents mentioning body weight as a major influence on health there was a complex interaction between the effects of age and educational level by gender (Table $2 \mathrm{~b}$ ). Tertiary-educated women were the least likely to mention body weight as an influence on health, and had, on average, a lower BMI in each age group (overall average BMI 25.7, 23.7 and 22.6 in primary, secondary and tertiary-educated women, respectively). There was no clear pattern for men, although the youngest age group among tertiaryeducated men was the least likely, and the oldest tertiary-educated men the most likely, to mention body weight as an influence on health.

The interactions between age, educational level and gender among those mentioning physical activity as an influence on health was also difficult to interpret (Table 2c). Middle-aged (45-54-year-old) men and women were generally the least likely to mention physical activity (except tertiary-educated women).

In order to summarize the complex interactions between country, education, gender and age, and to take into account the effects of BMI and smoking status, logistic regression analysis was used. All variables were categorized and the outcome variables were: 'risk' of doing no leisure activity and 'risk' of mentioning physical activity and body weight as influences on health (Table 3). This analytical approach allows an assessment of the independent effects of each factor in the model, adjusting for the effects of all the other factors in the model. The coefficients for the comparison of each level against the reference category are presented together with the 95\% confidence intervals. For some comparisons, particularly for country, the designation of the reference category is arbitrary and we have used Austria for two reasons: (1) it was the country listed first alphabetically, and (2) it had a low level of no recreational activity.

The interpretation of the relative risks for country suggests that the likelihood of not engaging in any recreational activity is 4.59 times greater in Belgium and 
Table 2a Percentage of respondents not participating in any recreational activity classified by education level and gender

\begin{tabular}{|c|c|c|c|c|c|c|}
\hline \multirow{3}{*}{$\begin{array}{l}\text { Age } \\
\text { group } \\
\text { (years) }\end{array}$} & \multicolumn{6}{|c|}{ Education level } \\
\hline & \multicolumn{2}{|c|}{ Primary } & \multicolumn{2}{|c|}{ Secondary } & \multicolumn{2}{|c|}{ Tertiary } \\
\hline & Male & Female & Male & Female & Male & Female \\
\hline $15-24$ & 25.4 & 35.8 & 14.9 & 25.1 & 14.9 & 20.2 \\
\hline $25-34$ & 39.5 & 41.8 & 29.6 & 31.6 & 17.4 & 34.1 \\
\hline $35-44$ & 37.5 & 48.4 & 25.3 & 33.3 & 16.9 & 20.1 \\
\hline $45-54$ & 40.9 & 44.5 & 30.1 & 32.3 & 33.9 & 23.7 \\
\hline $55-64$ & 34.6 & 37.9 & 22.3 & 39.2 & 20.2 & 20.8 \\
\hline $65+$ & 39.3 & 49.6 & 28.1 & 40.7 & 29.4 & 32.6 \\
\hline Total & 36.7 & 43.3 & 24.7 & 32.4 & 20.1 & 24.9 \\
\hline
\end{tabular}

All values weighted to adjust for different population sizes in each member state.

Table $\mathbf{2 b}$ Percentage of respondents mentioning body weight as the greatest influence on health classified by education level and gender

\begin{tabular}{|c|c|c|c|c|c|c|}
\hline \multirow{3}{*}{$\begin{array}{l}\text { Age } \\
\text { group } \\
\text { (years) }\end{array}$} & \multicolumn{6}{|c|}{ Education level } \\
\hline & \multicolumn{2}{|c|}{ Primary } & \multicolumn{2}{|c|}{ Secondary } & \multicolumn{2}{|c|}{ Tertiary } \\
\hline & Male & Female & Male & Female & Male & Female \\
\hline $15-24$ & 9.9 & 17.7 & 8.7 & 11.5 & 6.2 & 9.3 \\
\hline $25-34$ & 9.3 & 16.6 & 10.1 & 11.1 & 15.0 & 10.0 \\
\hline $35-44$ & 6.3 & 12.4 & 11.9 & 14.2 & 12.1 & 7.7 \\
\hline $45-54$ & 12.4 & 13.9 & 13.7 & 14.6 & 6.5 & 13.6 \\
\hline $55-64$ & 14.8 & 14.9 & 12.4 & 18.8 & 15.5 & 11.3 \\
\hline $65+$ & 13.4 & 16.4 & 15.3 & 16.4 & 16.0 & 10.2 \\
\hline Total & 11.7 & 15.1 & 11.4 & 13.7 & 11.5 & 9.9 \\
\hline
\end{tabular}

All values weighted to adjust for different population sizes in each member state.

Table 2c Percentage of respondents mentioning physical activity as the greatest influence on health classified by education level and gender

\begin{tabular}{|c|c|c|c|c|c|c|}
\hline \multirow{3}{*}{$\begin{array}{l}\text { Age } \\
\text { group } \\
\text { (years) }\end{array}$} & \multicolumn{6}{|c|}{ Education level } \\
\hline & \multicolumn{2}{|c|}{ Primary } & \multicolumn{2}{|c|}{ Secondary } & \multicolumn{2}{|c|}{ Tertiary } \\
\hline & Male & Female & Male & Female & Male & Female \\
\hline $15-24$ & 22.7 & 13.1 & 25.3 & 17.7 & 27.8 & 26.2 \\
\hline $25-34$ & 22.8 & 11.5 & 17.8 & 15.2 & 27.3 & 19.9 \\
\hline $35-44$ & 15.4 & 13.9 & 20.1 & 16.7 & 25.5 & 15.4 \\
\hline $45-54$ & 12.2 & 10.1 & 16.6 & 10.8 & 16.9 & 21.3 \\
\hline $55-64$ & 15.1 & 16.2 & 10.7 & 9.2 & 31.0 & 25.2 \\
\hline $65+$ & 19.8 & 13.5 & 20.2 & 18.6 & 21.9 & 26.7 \\
\hline Total & 17.2 & 13.6 & 18.9 & 15.0 & 25.6 & 21.3 \\
\hline
\end{tabular}

All values weighted to adjust for different population sizes in each member state.

over 9 times greater in Portugal than Austria, taking into account the effects of all the other factors in the model. Only in Sweden and Finland are people more likely to engage in recreational activity than in Austria. Adjusting for age, educational level, BMI and smoking did not remove the between-country differences apparent on univariate comparison, suggesting important residual country effects on the likelihood of engaging in recreational activities.

The group most likely to engage in recreational activities were young, educated men, who have a low BMI, do not smoke, believe activity is an important influence on health, and who come from Scandinavia. Those who were most likely to believe body weight was an important influence on health were more likely to be female, educated to a primary level, overweight (higher risk of mentioning body weight in the obese: 4.76) and ex- or non-smokers. Those who were most likely to mention physical activity were young, tertiary-educated males who are lean, do not smoke and are engaged in more recreational activities. 
Table 3 Effects of various factors on risk (relative risk, $\mathrm{RR}$, and $95 \%$ confidence intervals, $\mathrm{Cl}$ ) of participating in no leisure activities and in believing body weight and activity influence health*

\begin{tabular}{|c|c|c|c|c|c|c|}
\hline \multirow[b]{2}{*}{ Variable in model } & \multicolumn{2}{|c|}{ No leisure activity } & \multicolumn{2}{|c|}{$\begin{array}{l}\text { Body weight as } \\
\text { influence on health }\end{array}$} & \multicolumn{2}{|c|}{$\begin{array}{l}\text { Physical activity as } \\
\text { influence on health }\end{array}$} \\
\hline & RR & $(95 \% \mathrm{Cl})$ & $\mathrm{RR}$ & $(95 \% \mathrm{Cl})$ & $\mathrm{RR}$ & $(95 \% \mathrm{Cl})$ \\
\hline $\begin{array}{l}\text { Sex (male) } \\
\text { Female }\end{array}$ & 1.44 & $(1.41-1.46)$ & 1.18 & $(1.15-1.21)$ & 0.78 & $(0.76-0.79)$ \\
\hline $\begin{array}{l}\text { Age (15-24) } \\
25-34 \\
35-44 \\
45-54 \\
55-64 \\
65+\end{array}$ & $\begin{array}{l}1.70 \\
1.56 \\
1.82 \\
1.51 \\
2.41\end{array}$ & $\begin{array}{l}(1.65-1.75) \\
(1.51-1.60) \\
(1.77-1.88) \\
(1.46-1.56) \\
(2.33-2.49)\end{array}$ & $\begin{array}{l}0.96 \\
0.90 \\
0.91 \\
0.98 \\
1.08\end{array}$ & $\begin{array}{l}(0.92-1.00) \\
(0.86-0.93) \\
(0.87-0.95) \\
(0.94-1.02) \\
(0.94-1.02)\end{array}$ & $\begin{array}{l}0.79 \\
0.75 \\
0.55 \\
0.62 \\
0.70\end{array}$ & $\begin{array}{l}(0.76-0.81) \\
(0.72-0.77) \\
(0.53-0.57) \\
(0.60-0.64) \\
(0.68-0.73)\end{array}$ \\
\hline $\begin{array}{l}\text { Education (primary) } \\
\text { Secondary } \\
\text { Tertiary }\end{array}$ & $\begin{array}{l}0.65 \\
0.50\end{array}$ & $\begin{array}{l}(0.63-0.66) \\
(0.49-0.52)\end{array}$ & $\begin{array}{l}0.98 \\
0.88\end{array}$ & $\begin{array}{l}(0.95-1.00) \\
(0.85-0.92)\end{array}$ & $\begin{array}{l}1.05 \\
1.41\end{array}$ & $\begin{array}{l}(1.02-1.08) \\
(1.36-1.45)\end{array}$ \\
\hline $\begin{array}{l}B M I(<20) \\
20-24 \\
25-29 \\
30+\end{array}$ & $\begin{array}{l}0.99 \\
1.08 \\
1.38\end{array}$ & $\begin{array}{l}(0.97-1.02) \\
(1.05-1.12) \\
(1.33-1.43)\end{array}$ & $\begin{array}{l}1.49 \\
2.16 \\
4.76\end{array}$ & $\begin{array}{l}(1.42-1.55) \\
(2.06-2.26) \\
(4.52-5.00)\end{array}$ & $\begin{array}{l}1.44 \\
1.22 \\
0.93\end{array}$ & $\begin{array}{l}(1.39-1.49) \\
(1.18-1.27) \\
(0.89-0.98)\end{array}$ \\
\hline $\begin{array}{l}\text { Smoking (smoker) } \\
\text { Ex- (recent) } \\
\text { Ex- (long time ago) } \\
\text { Non }\end{array}$ & $\begin{array}{l}0.86 \\
0.66 \\
0.71\end{array}$ & $\begin{array}{l}(0.82-0.91) \\
(0.64-0.68) \\
(0.70-0.73)\end{array}$ & $\begin{array}{l}1.30 \\
1.09 \\
1.23\end{array}$ & $\begin{array}{l}(1.21-1.39) \\
(1.05-1.14) \\
(1.20-1.26)\end{array}$ & $\begin{array}{l}1.05 \\
1.69 \\
1.45\end{array}$ & $\begin{array}{l}(0.98-1.12) \\
(1.63-1.75) \\
(1.41-1.48)\end{array}$ \\
\hline $\begin{array}{l}\text { Body weight as } \\
\text { influence on health (no } \\
\text { Yes }\end{array}$ & 1.03 & $(1.00-1.05)$ & - & & 0.48 & $(0.46-0.49)$ \\
\hline $\begin{array}{l}\text { Activity as influence on } \\
\text { health (no) } \\
\text { Yes }\end{array}$ & 0.55 & $(0.54-0.56)$ & 0.48 & $(0.46-0.49)$ & - & \\
\hline $\begin{array}{l}\text { Activity level (no) } \\
\text { Yes }\end{array}$ & - & & 1.03 & $(1.00-1.06)$ & 0.55 & $(0.53-0.56)$ \\
\hline $\begin{array}{l}\text { Country (Austria) } \\
\text { Belgium } \\
\text { Denmark } \\
\text { Finland } \\
\text { France } \\
\text { Germany } \\
\text { Greece } \\
\text { Ireland } \\
\text { Italy } \\
\text { Luxembourg } \\
\text { Netherlands } \\
\text { Portugal } \\
\text { Spain } \\
\text { Sweden } \\
\text { UK }\end{array}$ & $\begin{array}{l}4.59 \\
1.65 \\
0.61 \\
3.98 \\
2.50 \\
4.21 \\
1.15 \\
4.25 \\
1.21 \\
1.36 \\
9.15 \\
3.16 \\
0.73 \\
2.30\end{array}$ & $\begin{array}{l}(4.21-5.01) \\
(1.48-1.83) \\
(0.53-0.70) \\
(3.69-4.30) \\
(2.32-2.70) \\
(3.86-4.59) \\
(1.00-1.32) \\
(3.94-4.59) \\
(0.95-1.75) \\
(1.24-1.49) \\
(8.38-9.99) \\
(2.92-3.42) \\
(0.66-0.82) \\
(2.13-2.49)\end{array}$ & $\begin{array}{l}3.16 \\
1.72 \\
0.95 \\
2.09 \\
1.67 \\
2.03 \\
2.98 \\
1.11 \\
1.10 \\
1.68 \\
1.98 \\
0.95 \\
2.00 \\
2.14\end{array}$ & $\begin{array}{l}(2.84-3.52) \\
(1.51-1.97) \\
(0.81-1.10) \\
(1.90-2.31) \\
(1.52-1.84) \\
(1.82-2.26) \\
(2.60-3.41) \\
(1.01-1.22) \\
(0.74-1.66) \\
(1.51-1.87) \\
(1.77-2.21) \\
(0.86-1.05) \\
(1.79-2.25) \\
(1.95-2.36)\end{array}$ & $\begin{array}{l}0.67 \\
2.31 \\
2.78 \\
0.59 \\
1.01 \\
0.39 \\
1.66 \\
0.37 \\
0.42 \\
0.65 \\
0.56 \\
0.71 \\
1.48 \\
1.28\end{array}$ & $\begin{array}{l}(0.53-0.56) \\
(2.11-2.52) \\
(2.55-3.03) \\
(0.55-0.63) \\
(0.95-1.08) \\
(0.35-0.43) \\
(1.50-1.84) \\
(0.35-0.43) \\
(0.29-0.60) \\
(0.60-0.70) \\
(0.51-0.62) \\
(0.66-0.76) \\
(1.38-1.61) \\
(1.20-1.37)\end{array}$ \\
\hline
\end{tabular}

*Logistic regression analysis was used, with all the other variables included in the model listed. The reference category is given in italic in brackets.

\section{Discussion}

As far as we are aware this is the first pan-European survey of attitudes about the effects of physical activity and body weight on health. The main findings to emerge from this study are that compared with other influences on health, people across Europe do not perceive body weight to be a major influence on health. People are a little more likely to mention physical activity, but the majority perceived the most important influences on health to be smoking, food and stress.
Respondents may be motivated to take up recreational activities to reduce stress, and this may need to be taken into account when promoting the benefits of physical activity.

There was wide variation across Europe in the proportions of respondents mentioning either body weight or activity as an influence on health, as well as in the proportion not engaged in any recreational activities. Overall, around 30\% of respondents did not engage in any recreational activities; respondents who were more physically active at work or during the day 
were less likely to engage in recreational activities. This seems reasonable, and suggests the need for a more holistic assessment of activity to establish the true levels of activity over the whole day or to cover usual patterns. It may, therefore, be misleading to interpret recreational levels of activity as an appropriate marker of overall activity patterns.

The sample size and sampling strategy, and the way the data were weighted, should provide information that reflects the situation in each country and across Europe. The cross-sectional design used limits the causal inferences that can be drawn from the data, trends and associations should be interpreted with caution. There may have been some variation between countries in how respondents understood what was covered by the way physical activity and exercise were linked in the questions asked. There has been a lack of clarity as to what is meant by physical activity, exercise and fitness and this may be confusing the general public $^{13}$

Although more recently there has been increasing consistency in the messages given about the benefits of promoting low-intensity walking and other activities ${ }^{14,15}$, the age, educational level and gender differences reported in the present study suggest that this message may not have got across to the general public. Different activities and approaches are likely to be effective in different age groups ${ }^{16}$.

Those who were most likely to mention physical activity were young, tertiary-educated males who were lean, did not smoke and were engaged in more recreational activities. Those who were most likely to believe body weight was an important influence on health were more likely to be female, educated to a primary level, overweight and ex- or non-smokers. Adjusting for all the above factors, there were still large between-country differences in the proportions mentioning either body weight or physical activity. It is not easy to see any obvious trends in the country patterns, although there was some suggestion that the southern European countries were less likely to mention activity and body weight as influences on health.

The rise in obesity, and decline in levels of physical activity, have clear and important public health implications. The results of the present study suggest that a simple European-wide approach may not be effective. The results suggest that there are complex interactions of attitudes and beliefs that need to be addressed in different ways in different groups of people in different countries.

\section{References}

1 World Health Organization. Obesity. Preventing and Managing the Global Epidemic. Report of a WHO consultation on obesity. Geneva: WHO, 1998.

2 Manson JE, Willett WC, Stampfer MJ. Body weight and mortality among women. N. Engl.J. Med. 1995; 333: 677-85.

3 Williamson DF. Dietary intake and physical activity as 'predictors' of weight gain in observational, prospective studies. Nutr. Rev. 1996; 54: S101-9.

4 Cowburn G, Hillsdon M, Hankey CR. Obesity management by lifestyle strategies. Br. Med. Bull. 1997; 53: 389-408.

5 Prentice AM, Jebb SA. Obesity in Britain: gluttony or sloth. BMJ 1995; 311: 437-9.

6 Eaton CB, Menard LM. A systematic review of physical activity promotion in primary acre settings. Br.J. Sports Med. 1998; 32: 11-16.

7 Hillsdon M, Thorogood M. A systematic review of physical activity promotion strategies. Br. J. Sports Med. 1996; 30: 84-9.

8 Haapanen N, Milunpalo S, Vuori I, Oja P, Pasanen M. Association of leisure time physical activity with the risk of coronary heart disease, hypertension and diabetes in middle-aged men and women. Int. J. Epidemiol. 1997; 26: 739-47.

9 Van Mechelen W. Can running injuries be effectively prevented? Sports Med. 1995; 19: 161-5.

10 Young DR, Haskell WL, Taylor CB, Fortmann SP. Effect of community health education on physical activity knowledge, attitudes, and behaviour. The Stanford Five-City Project. Am. J. Epidemiol. 1996; 144: 264-74.

11 Kearney JM, Kearney MJ, McElhone S, Gibney MJ. Methods used to conduct the pan-European Union survey on consumer attitudes to physical activity, body weight and health. Public Health Nutr. 1999; 2: 79-86.

12 Moser CA, Kalton G. Survey Methods in Social Investigation, 2nd edn. London: Heineman Educational Books, 1971.

13 Wareham NJ, Hennings SJ, Byrne CD, Hales CN, Prentice AM, Day NE. A quantitative analysis of the relationship between habitual energy expenditure, fitness and the metabolic cardiovascular syndrome. Br. J. Nutr. 1998; 80: 235-41.

14 American College of Sports Medicine Position Stand. Exercise and physical activity for older adults. Med. Sci. Sports Exerc. 1998; 30: 992-1008.

15 American College of Sports Medicine Position Stand. The recommended quantity and quality of exercise for developing and maintaining cardiorespiratory and muscular fitness, and flexibility in healthy adults. Med. Sci. Sports Exerc. 1998; 30: 955-91.

16 Booth ML, Bauman A, Owen N, Gore CJ. Physical activity preferences, preferred sources of assistance, and perceived barriers to increased activity among physically inactive Australians. Prev. Med. 1997; 26: 131-7. 